\title{
Recurrent pregnancy loss: current perspectives
}

This article was published in the following Dove Press journal:

International Journal of Women's Health

17 May 2017

Number of times this article has been viewed

\author{
Hady El Hachem ${ }^{1,2}$ \\ Vincent Crepaux ${ }^{3}$ \\ Pascale May-Panloup ${ }^{4}$ \\ Philippe Descamps ${ }^{3}$ \\ Guillaume Legendre ${ }^{3}$ \\ Pierre-Emmanuel Bouet ${ }^{3}$ \\ 'Department of Reproductive \\ Medicine, Ovo Clinic, Montréal, QC, \\ Canada; ${ }^{2}$ Department of Obstetrics \\ and Gynecology, University of \\ Montreal, Montréal, QC, Canada; \\ ${ }^{3}$ Department of Obstetrics and \\ Gynecology, Angers University \\ Hopsital, Angers, France; ${ }^{4}$ Department \\ of Reproductive Biology, Angers \\ University Hospital, Angers, France
}

Correspondence: Hady El Hachem Department of Reproductive Medicine, Ovo Clinic, Université de Montréal 8000 Boulevard Decarie, Montréal, QC H4P 2S4, Canada

Tel + I 961337701 I

Email hadyhachem@hotmail.com
Abstract: Recurrent pregnancy loss is an important reproductive health issue, affecting $2 \%-5 \%$ of couples. Common established causes include uterine anomalies, antiphospholipid syndrome, hormonal and metabolic disorders, and cytogenetic abnormalities. Other etiologies have been proposed but are still considered controversial, such as chronic endometritis, inherited thrombophilias, luteal phase deficiency, and high sperm DNA fragmentation levels. Over the years, evidence-based treatments such as surgical correction of uterine anomalies or aspirin and heparin for antiphospholipid syndrome have improved the outcomes for couples with recurrent pregnancy loss. However, almost half of the cases remain unexplained and are empirically treated using progesterone supplementation, anticoagulation, and/or immunomodulatory treatments. Regardless of the cause, the long-term prognosis of couples with recurrent pregnancy loss is good, and most eventually achieve a healthy live birth. However, multiple pregnancy losses can have a significant psychological toll on affected couples, and many efforts are being made to improve treatments and decrease the time needed to achieve a successful pregnancy. This article reviews the established and controversial etiologies, and the recommended therapeutic strategies, with a special focus on unexplained recurrent pregnancy losses and the empiric treatments used nowadays. It also discusses the current role of preimplantation genetic testing in the management of recurrent pregnancy loss.

Keywords: recurrent pregnancy loss, recurrent miscarriage, antiphospholipid syndrome, preimplantation genetic screening, preimplantation genetic diagnosis

\section{Introduction}

Early pregnancy loss, also referred to as miscarriage or spontaneous abortion, is defined as the loss of a clinical pregnancy before 20 completed weeks of gestational age (18 weeks after fertilization) or, if gestational age is unknown, the loss of an embryo/fetus of $<400$ g. ${ }^{1}$ Ectopic, molar, and biochemical pregnancies are thus not included. ${ }^{2}$ It is a relatively common event, occurring in $15 \%-25 \%$ of pregnancies, and increasing in prevalence with maternal age. ${ }^{2,3}$ Indeed, the risk is between $9 \%$ and $12 \%$ in women aged $\leq 35$ years, but increases to $50 \%$ in women aged $>40 .{ }^{3}$ Several nomenclatures have been used by different societies. ${ }^{4,5}$ Miscarriage can be further classified as embryonic loss (or early miscarriage) when it occurs before 10 gestational weeks and fetal loss (or fetal miscarriage) when it occurs after 10 gestational weeks, because factors associated with each may differ. ${ }^{4,5}$ The definition of recurrent pregnancy loss (RPL) has long been debated and differs among international societies. For the European Society for Human Reproduction and Embryology ${ }^{4,6}$ and the Royal College of Obstetricians and Gynaecologists, ${ }^{7}$ RPL refers to three consecutive pregnancy losses, including nonvisualized ones. However, according to the American Society for Reproductive Medicine, ${ }^{2}$ it is defined as two or more clinical pregnancy losses (documented by ultrasonography or histopathologic examination), but not necessarily consecutive. 
RPL is an important reproductive health issue, because it affects $2 \%-5 \%$ of couples. ${ }^{2,7}$ The incidence of RPL varies widely between reports because of the differences in the definitions and criteria used, as well as the populations' characteristics. Primary RPL refers to multiple losses in a woman with no previous viable infants, whereas secondary RPL refers to multiple losses in a woman who has already had a pregnancy beyond 20 gestational weeks. Tertiary RPL refers to multiple pregnancy losses between normal pregnancies., ${ }^{4}$

This review will discuss the various etiologies of RPL, their pathophysiology and diagnosis, as well as recommended and controversial treatments, with a special focus on unexplained RPL (URPL) and the current and future role of genetic testing.

\section{Etiologies}

\section{Uterine factors}

\section{Anatomic defects}

Uterine anomalies are reportedly found in up to $19 \%$ of women with $\mathrm{RPL}^{8}$ and can be classified as acquired or congenital.

Acquired abnormalities include intrauterine adhesions, myomas, and endometrial polyps. Intrauterine adhesions, or synechiae, occur in sites where the endometrial basal layer has been destroyed, most frequently following curettage, a uterine surgery or infection, or a complicated birth. ${ }^{9}$ The frequency and severity of adhesions increase with the number of curettages. ${ }^{9}$ Studies have shown that adhesiolysis significantly decreases miscarriage rates and is the preferred treatment for women with RPL. ${ }^{8}$ However, to date, there is no consensus regarding the surgical method, the instruments and physical barriers used to prevent recurrence, and the hormonal treatment required for endometrial regeneration. ${ }^{9}$ Myomas are classified according to their position in the uterus (submucosal, intramural, or subserosal) ${ }^{10}$ and cause RPL via mechanical and molecular mechanisms. ${ }^{11}$ Submucosal myomas are reportedly found in $4.5 \%$ of women with RPL and should be surgically removed whenever diagnosed. ${ }^{12}$ Polyps are found in 2\%-3\% of women with RPL and should be hysteroscopically resected. ${ }^{13}$ Cervical incompetence usually causes second trimester losses, and it can be acquired following surgical trauma or is associated with congenital uterine abnormalities. ${ }^{12}$

Congenital abnormalities are the consequence of an abnormal development of the Müllerian ducts and include septate, bicornuate, unicornuate, didelphic, and arcuate uteri. They are reportedly found in up to $10 \%$ of women with RPL. ${ }^{12}$ The two most widely used classifications are the American Fertility Society/American Society for Reproductive Medicine ${ }^{14}$ and the European Society for Human Reproduction and Embryology/European Society for Gynecological Endoscopy classifications. ${ }^{15}$ Congenital anomalies are found in $8.4 \%-12.6 \%$ of women with RPL, which is seven to eight times higher than the general population. ${ }^{12,16}$ There is a lack of randomized controlled trials (RCTs) concerning the impact of uterine metroplasty on reproductive outcomes in women with congenital uterine anomalies and RPL. Septate uterus is the most common type and is associated with a chance of spontaneous miscarriage. ${ }^{16}$ There is evidence to suggest improved pregnancy rates following metroplasty, ${ }^{17}$ and it is recommended to surgically remove septa in women with RPL. ${ }^{2,12,17}$ The prevalence of arcuate uteri is the same as the general population, and their impact on reproductive outcome remains controversial. ${ }^{16}$ Therefore, arcuate metroplasty is not recommended in women with RPL. 2,12,7 The other congenital abnormalities are more commonly associated with third trimester pregnancy loss and preterm birth, and the decision to treat or not is more complex. ${ }^{16}$ Metroplasty is not recommended for unicornuate uteri, is highly controversial for didelphys, and is only recommended as a last resort for bicornuate uteri. ${ }^{18,19}$ Finally, it should be noted that for women with RPL secondary to irreversible uterine anatomic defects, the use of a gestational carrier is a viable option.

\section{Chronic endometritis}

Chronic endometritis (CE) is defined as chronic inflammation of the endometrial lining, and some studies have shown an increased prevalence in women with RPL (10\%-27\%). ${ }^{20-22}$ Endometrial receptivity is thought to be impaired by the stromal infiltration of plasma cells, as well as altered expressions of genes involved in implantation, leading to RPL but also infertility and recurrent implantation failure following in vitro fertilization (IVF). ${ }^{22}$ Several methods have been used to confirm the diagnosis of CE, but the gold standard is identification of plasma cells in the endometrial stroma, using immunohistochemistry stains for syndecan-1 (CD138), a marker of plasma cells ( $\geq 5$ on 10 nonoverlapping high-power field). ${ }^{22}$ The etiology is most likely infectious, and many treatment regimens with antibiotics have been proposed, the most widely used being doxycycline (200 mg per day for 14 days), with some studies reporting favorable outcomes following treatment. ${ }^{20-22}$ However, no randomized trials have been published to date, and controversies remain concerning the impact of $\mathrm{CE}$ on reproductive outcome, the patient population to screen, the treatment regimen, and the 
need for a biopsy to confirm resolution. Given the lack of conclusive evidence, several international societies do not include screening for CE in their recommendations. ${ }^{2,7}$ Several other infections have been investigated as potential causes of early miscarriage. There is some evidence that bacterial vaginosis (Mycoplasma hominis, Ureaplasma urealyticum), brucellosis, syphilis, cytomegalovirus, dengue fever, human immunodeficiency virus, rubella, and malaria are more frequently found in women with spontaneous miscarriage. ${ }^{23}$ However, no causal link has been established, and it is not recommended to test or empirically treat asymptomatic women with RPL.,23

\section{Antiphospholipid syndrome}

Antiphospholipid syndrome (APS) is characterized by the presence of antiphospholipid antibodies (aPL) and has long been associated with RPL. Indeed, pregnancy morbidity is one of the two clinical criteria required to confirm the diagnosis of APS, the other being vascular thrombosis (Table 1). ${ }^{24}$ The prevalence of APS in women with RPL varies according to studies, from as low as $6 \%$ to as high as $42 \%$, but it is generally accepted to be $5 \%-20 \% \cdot{ }^{25-27}$ This is probably explained by the use of nonstandardized laboratory-specific assays, and the different types of antibodies tested over the years. However, the only ones currently used for the diagnosis of APS are lupus anticoagulant, anticardiolipin antibody, and anti- $\beta 2$ glycoprotein I. ${ }^{24,27}$ APS is referred to as primary in patients with no underlying disease and secondary when associated with other conditions..$^{24}$ aPL are also associated with other obstetric complications, such as preeclampsia, intrauterine growth restriction, and prematurity, ${ }^{24}$ and several mechanisms have been proposed. aPL target the trophoblast, causing an impaired trophoblastic invasion and inappropriate secretion of human chorionic gonadotropin and growth factor, ${ }^{28}$ as well as inducing syncytiotrophoblast apoptosis ${ }^{29}$ and an inflammatory response via complement activation at the maternal-fetal interface. ${ }^{30}$ They also target the vascular endothelium and cause abnormal formation of the spiral arteries. ${ }^{29}$ Although the three types of antibodies are associated with RPL and obstetric complications, the risk and severity vary with the different types and associations of antibodies according to some studies. ${ }^{31,32}$ Screening for aPL is part of the initial workup in patients with RPL.,

Many therapeutic approaches have been proposed over the years and include aspirin, unfractionated heparin, low-molecular-weight heparin (LMWH), corticosteroids, intravenous immunoglobulins (IVIg), and combinations of the above. The current standard treatment for RPL is low-dose aspirin and heparin..$^{2,73}$ In vitro and animal studies have shown that the therapeutic effects of heparin are the consequences of local actions and are independent of its anticoagulant properties. Indeed, heparin can inhibit the antibodies from binding to the trophoblast, prevent complement activation, and promote trophoblastic invasiveness. ${ }^{33,34}$

Table I Diagnostic criteria for APS according to "the International consensus statement on an update of the classification criteria for definite antiphospholipid syndrome"

International consensus classification criteria for the APS

At least I clinical and I laboratory criteria must be present for definite APS

Clinical criteria

I - Vascular thrombosis

One or more clinical episodes of an arterial, venous, or small vessel thrombosis, in any tissue or organ. Thrombosis must be confirmed by imaging or Doppler studies or histopathology, with the exception of superficial venous thrombosis. For histopathologic confirmation, thrombosis should be without significant evidence of inflammation in the vessel wall.

II - Obstetric morbidity

I) One or more unexplained demise of a morphologically normal fetus at or beyond 10 weeks of gestation, with normal fetal morphology documented by ultrasound or by direct examination, or

2) One or more premature births of a morphologically normal neonate before the 34th week of gestation, because of a) eclampsia or severe preeclampsia or b) placental insufficiency, or

3) Three or more unexplained consecutive miscarriages of $<10$ weeks of gestation. Known factors associated with recurrent miscarriage, including parental genetic, anatomic, and endocrinologic factors should be ruled out.

Laboratory criteria $\mathrm{I}-\mathrm{aCL}$ (IgG and/or IgM) in the blood, present in medium or high titers (>40 GPL or MPL or >99th percentile), on two or more occasions, at least 12 weeks apart, measured by a standardized ELISA.

II - Anti- $\beta 2$ GPI antibody of IgG and/or IgM isotype in the blood ( $>99$ th percentile) on two or more occasions, at least 12 weeks apart, measured by a standardized ELISA.

III - Lupus anticoagulant present in plasma, on two or more occasions at least 12 weeks apart, detected according to the guidelines of the International Society on Thrombosis and Hemostasis.

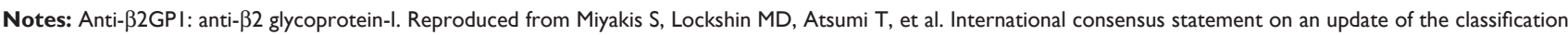
criteria for definite antiphospholipid syndrome (APS). J Thromb Haemost. 2006;4(2):295-306, with permission from John Wiley and Sons, copyright 2006. ${ }^{24}$ Abbreviations: APS, antiphospholipid syndrome; aCL, anticardiolipin antibody; ELISA, enzyme-linked immunosorbent assay. 
Moreover, the doses used to prevent obstetric complications are lower than those used for anticoagulation. Heparin treatment should be started with the positive pregnancy test, at a dose of 5,000-7,500 IU twice daily, continued until delivery, and resumed postpartum for $4-6$ weeks. ${ }^{33,35}$ It is associated with thrombocytopenia and osteopenia. Therefore, a baseline platelet count and a partial thromboplastin time should be obtained and checked regularly during pregnancy, and daily calcium $(1,200 \mathrm{mg})$ and vitamin D (800-1,000 IU) intake increased. Aspirin (81 mg daily) should be initiated before conception, discontinued 4 weeks before the expected delivery date, and resumed postpartum for life. ${ }^{33,35}$ Many studies have confirmed that the combined treatment of aspirin and heparin increases the live birth rate (LBR) compared to aspirin alone. ${ }^{36-38} \mathrm{LMWH}$ was more recently suggested as an alternative to heparin, and early studies suggested similar efficiency and safety. ${ }^{39,40}$ However, large RCTs comparing the two regimens are still lacking in this specific group of patients. The use of prednisone has been abandoned because several studies failed to show any improvement in outcomes while increasing the risk of gestational hypertension and diabetes. ${ }^{41}$ It is worth noting that women with RPL due to APS remain at risk for late pregnancy complications despite the treatment, and thus should be monitored accordingly. Finally, because of their increased risk for vascular thrombosis, women should be advised against using estrogen-containing contraceptive pills and use progestin only pills, and they should refrain from smoking. ${ }^{33,35}$

\section{Inherited thrombophilias}

Inherited thrombophilias refer to conditions that increase the risk of venous thromboembolism, secondary to a genetic alteration of a functional protein in the coagulation cascade. These include factor V Leiden (FVL), prothrombin gene (PT G20210A) mutation, protein C and protein S deficiency (PSD), antithrombin III (ATIII) deficiency, and methyltetrahydrofolate reductase (MTHFR) mutation. ${ }^{42}$ Screening for inherited thrombophilias is recommended in pregnant women with a history of venous thromboembolism. ${ }^{42,43}$ However, the association with RPL remains controversial. A 2003 meta-analysis of 31 studies found FVL, PT, and PSD to be associated with RPL. ${ }^{44}$ Other early retrospective studies and meta-analyses also found various levels of association. ${ }^{44} 46$ However, prospective studies failed to confirm the correlation. ${ }^{47,48}$ A recent meta-analysis of eight trials including 483 patients with inherited thrombophilias and RPL showed no benefit of LMWH in preventing RPL. ${ }^{49}$ Another meta-analysis of nine studies including 1,228 women with a history of at least two miscarriages, with or without inherited thrombophilias, failed to show any positive impact of anticoagulation treatment (aspirin, LMWH, or the combination of both).$^{50}$ It is therefore not recommended to test or treat women with RPL for inherited thrombophilias. ${ }^{2,43}$ However, a recent survey of obstetricians and reproductive endocrinologists in the United States showed that $46 \%$ screen patients with a single loss at $<20$ weeks of gestation for inherited thrombophilias, and the vast majority used heparin and/or aspirin for treatment. ${ }^{51}$

\section{Endocrine factors}

Hyperprolactinemia is associated with infertility and miscarriage, by altering the hypothalamic-pituitary-ovarian axis, thus leading to impaired folliculogenesis and anovulation. ${ }^{52}$ Treatment of the underlying cause restores normal fertility. For women with idiopathic hyperprolactinemia and RPL, one small RCT found that treatment with dopamine agonists (bromocriptine $2.5-5 \mathrm{mg} /$ day until 9th week of gestation) significantly decreased miscarriage rates (risk ratio $[R R]=0.28$ ) compared to no treatment. LBRs, however, were comparable. ${ }^{53}$ This is the only trial on the subject, and the quality of the evidence is considered low. ${ }^{54}$

Thyroid disorders, especially hypothyroidism, have long been associated with infertility, adverse pregnancy outcomes, and RPL. ${ }^{55}$ Overt hypothyroidism is easily diagnosed and treated. However, there are conflicting data concerning the association between subclinical hypothyroidism and pregnancy loss. ${ }^{55-57}$ Nowadays, the most commonly used serum thyroid-stimulating hormone (TSH) threshold to define subclinical hypothyroidism is $>2.5 \mathrm{mIU} / \mathrm{L} .{ }^{58}$ Two recent cohort studies found a high prevalence of subclinical hypothyroidism (defined as TSH $>2.5 \mathrm{mIU} / \mathrm{L}$ ) in women with RPL (19\% and 21\%). However, LBRs in these patients were comparable with euthyroid women. ${ }^{59,60}$ Despite the lack of RCTs, it is recommended to keep $\mathrm{TSH}<2.5 \mathrm{mIU} / \mathrm{L}$ in these patients. ${ }^{58}$ Some studies have also found an association between thyroid antibodies and RPL in euthyroid patients, ${ }^{61-63}$ with evidence of a trend toward decreased miscarriage rates following treatment. ${ }^{64}$ However, to date, there is insufficient evidence to recommend routine screening of thyroid antibodies in euthyroid women with RPL. ${ }^{2,7,58}$

Polycystic ovarian syndrome (PCOS) is associated with an increased risk of miscarriage. ${ }^{65}$ Many mechanisms are thought to be involved, including insulin resistance and hyperinsulinemia, hyperandrogenemia, or increased 
plasminogen activator inhibitor-1 activity ${ }^{65}$ Lifestyle modifications, including weight reduction and exercise, improve insulin resistance and could thus decrease the risk of miscarriage. Metformin, an insulin-sensitizing drug, is commonly used in women with PCOS and has been shown to improve weight management and glucose tolerance, reduce androgen production, and enhance fertility ${ }^{66}$ Studies on its efficiency in decreasing the risk of miscarriage in women with PCOS have yielded conflicting results, ${ }^{67-70}$ and there is insufficient evidence to recommend it for RPL. However, metformin is frequently prescribed in women with PCOS, is safe during pregnancy, ${ }^{66}$ and, along with weight loss, could be useful to PCOS patients with RPL.

Uncontrolled diabetes has been shown to increase the risk of miscarriage, whereas an adequate preconceptual control significantly decreases the risk back to normal.,71

Luteal phase deficiency (LPD), or insufficiency, first described in $1949,{ }^{72}$ has been proposed as a cause of early miscarriage and RPL, but its definition and true impact on pregnancy rates remain highly controversial. The defining characteristic is a deficiency of endogenous progesterone or its action on the endometrium in the luteal phase, thus impairing normal implantation. Many mechanisms have been proposed, such as inadequate follicular growth, dysovulation, poor corpus luteum function, and abnormal endometrial response and receptivity. ${ }^{73,74}$ Medical conditions altering the hypothalamic-pituitary-ovarian axis and gonadotropin secretion are also thought to cause LPD, such as thyroid disease and hyperprolactinemia. ${ }^{52,57}$ Several diagnostic criteria have been used over the years: histologic dating of endometrial biopsies, luteal phase progesterone concentration, length of the luteal phase ( $<11$ days), and basal body temperature. This has led to discordant incidences in women with RPL, varying from $12 \%$ to $28 \%{ }^{73-76}$ However, diagnostic tests for LPD are neither reproducible nor reliable and have not been validated in large studies, and are thus not recommended in clinical practice., $, 7,75,76$ There is also no consensus on the proposed management of LPD. Besides treating the underlying cause, several therapeutic regimens have been used: ovulation induction, supplemental progesterone, supplemental progesterone and estrogen, and human chorionic gonadotropin. ${ }^{75-78}$ Progesterone supplementation is the most widely used treatment because of its availability, ease of administration, and tolerability. Details on progesterone treatment for RPL are discussed later.

\section{Environmental and psychological factors}

Several environmental factors have been associated with an increased risk of miscarriage: Obesity, defined as a body mass index $>30 \mathrm{~kg} / \mathrm{m}^{2},{ }^{79,80}$ smoking, ${ }^{81}$ excessive caffeine consumption ( $>300 \mathrm{mg} /$ day, or the equivalent of two cups), ${ }^{81,82}$ excessive alcohol intake, ${ }^{81,82}$ and cocaine.$^{83}$ Mildto-moderate alcohol intake is not associated with increased risk ${ }^{84} \mathrm{~A}$ healthy lifestyle with minimal exposure to these factors should thus be encouraged in women with RPL. ${ }^{2,7}$

RPL can have a significant psychological toll on the affected couple's personal and professional life, and various feelings have been reported, such as grief and depression, hopelessness, guilt, anxiety, and anger toward the partner, friends, or the treating physician. ${ }^{85}$ Several reports have looked at a possible psychological etiology for RPL, but such associations are very difficult to prove with the presence of various variables and confounding factors. One study found that depression increased the risk of early miscarriage, ${ }^{86}$ but overall results have been inconclusive. ${ }^{2,7}$ However, some studies have shown that psychological support is important in couples with RPL..$^{87,88}$ The concept of tender loving care refers to psychological support with weekly medical and ultrasonography examinations, and instructions to avoid heavy work, travel, and sexual activity. International societies recommend offering supportive care in dedicated clinics for couples with RPL., ${ }^{2,7}$

\section{Genetic factors}

The vast majority of early pregnancy losses $(50 \%-60 \%)$ are the consequence of chromosomal abnormalities, which can be of parental origin, or arise de novo in the embryo from parents with normal chromosomes. ${ }^{89,90}$

The most common parental abnormalities are balanced translocations, found in $2 \%-4 \%$ of cases of RPL, compared to $0.7 \%$ in the general population..$^{91,92}$ They can be reciprocal ( $60 \%$ ), involving the exchange of genetic material from one chromosome to another, or Robertsonian $(\sim 40 \%)$, where the long arms of two acrocentric chromosomes incorrectly share a centrosome. ${ }^{91,92}$ Paracentric and pericentric inversions are much rarer but are also associated with an increased risk of RPL. ${ }^{91,92}$ All balanced translocations can be detected by ordering a peripheral karyotyping in parents.

Parents carrying balanced translocations are usually asymptomatic. The karyotype of their product of conception (POC) can be entirely normal or have a balanced or an unbalanced translocation. Pregnancies with unbalanced translocations usually end in miscarriage - which is often seen as a natural selection mechanism - but can also lead to stillbirths, or even live births with major congenital defects..$^{89-92}$ It is difficult to estimate the percentage of each possibility because karyotypes on miscarried POC are not 
routinely ordered, but studies estimate that about 25\%-39\% have unbalanced translocations..$^{93,94}$ Moreover, data from embryo biopsies report that $\sim 25 \%$ have normal karyotypes, confirming the high level of chromosomal abnormalities in these embryos. ${ }^{95}$ Overall, despite the increased risk of pregnancy loss, most couples with balanced translocations end up with healthy live births. ${ }^{93}$

Embryonic aneuploidy is the most common cause of early pregnancy loss ( $<10$ weeks). Indeed, up to $90 \%$ of chromosomally abnormal embryos are spontaneously aborted, another natural selection mechanism. The most commonly found abnormalities are numeric chromosome errors, such as trisomy, polyploidy, and monosomy X. The risk of aneuploidy significantly increases with maternal age..$^{2,3,89}$

Because most cases are de novo errors, the risk of an embryo aneuploidy occurring in a subsequent pregnancy is low, and the higher the number of miscarriages, the less likely they are to be related to chromosomal abnormalities. ${ }^{96}$ The incidence of embryo chromosomal abnormalities is thus lower in women with RPL than in those with sporadic miscarriages. ${ }^{97}$

\section{Preimplantation genetic testing (PGT) for RPL due to balanced translocations}

PGT involves performing a controlled ovarian hyperstimulation cycle, followed by mature oocyte retrieval and IVF with the partner's sperm. The resulting embryos are then biopsied, either at the eight-cell cleavage stage where a single blastomere is removed or at the blastocyst stage where many trophectoderm cells are removed. The embryonic DNA is then tested for genetic abnormalities, and only the embryos with the normal DNA are later transferred into the uterine cavity. When the genetic defect is already known, such as cases of parental balanced translocations, the process is referred to as preimplantation genetic diagnosis (PGD). However, when no genetic abnormality is identified in the parents, a comprehensive chromosome screening is performed to determine which embryos are euploid, to be later transferred, and the process is referred to as preimplantation genetic screening (PGS). ${ }^{98}$

PGD for RPL secondary to parental chromosomal abnormalities has been used for many years, despite the lack of consensus regarding its efficiency and its superiority to expectant management. It is indeed difficult to compare the outcomes from PGD and non-PGD studies, whether in the same couples (before and after PGD) or in different populations. Moreover, couples with RPL referred to PGD probably have a longer and more complicated history of miscarriages and have higher risk translocations. ${ }^{99}$ It is important to note that expectant management yields encouraging results. Indeed, Franssen et a ${ }^{100}$ compared the reproductive outcome without PGD intervention between 278 carrier couples and 427 noncarrier couples with RPL. Despite a significantly lower pregnancy rate in carrier couples for the first and second pregnancies after parental chromosome analysis, and despite a significantly higher miscarriage rate among carrier couples ( $49 \%$ vs $30 \%$ ), the percentage of couples with at least one healthy child was comparable between carriers and noncarriers ( $83 \%$ vs $84 \%$ ) after a mean follow-up of 5.8 years. ${ }^{100}$ Moreover, the study found a very low risk of viable offspring with unbalanced chromosomal abnormalities in carrier couples, most of which can be detected at prenatal diagnosis. ${ }^{100}$

Data from large studies on PGD for all patients with balanced translocations and not only in couples with RPL, show an LBR of $\sim 25 \%-27 \%$ per embryo transfer, and $\sim 72 \%$ following a positive pregnancy test. ${ }^{95,101}$ These results suggest that once a positive pregnancy test is detected, PGD decreases the miscarriage rate to that of the general population. ${ }^{101}$ Fischer et al, ${ }^{102}$ in one of the largest studies to date, looked at the outcomes in 192 patients with more than three pregnancy losses undergoing 272 cycles of PGD for either a reciprocal translocation or Robertsonian translocation. Thirty-five percent of patients achieved a pregnancy, of which $13 \%$ ended in miscarriage. The LBR was $22 \%$ per cycle started, and the cumulative LBR after 1.4 cycles was $31 \%$. When comparing these data with those from patients with RPL who attempted spontaneous pregnancies, the study showed a significant decrease in the miscarriage rate $(13 \%$ vs $26 \%-64 \%)$ and a significant decrease in the estimated time needed to achieve an ongoing pregnancy (1.4 IVF cycles or $<4$ months vs 6 years). ${ }^{102}$ However, Scriven et $\mathrm{al}^{103}$ prospectively followed 59 couples with balanced translocations who underwent 132 IVF/PGD cycles and reported a 20\% LBR per started cycle. They also found that up to three stimulation cycles per couple would give a $50 \%$ chance of a successful live birth, while reducing the risk of miscarriage to the level of the general population. ${ }^{103}$ Two systematic reviews found LBR following PGD to be $31 \%-35 \%$ compared to $55 \%-74 \%$ following natural conception and medical management, and thus concluded that there was insufficient data to support systematic PGD in couples with RPL and balanced translocations. ${ }^{99,104}$ More recently, Ikuma et $\mathrm{al}^{105}$ have compared outcomes between 52 patients with RPL and balanced translocations who had natural conception and 37 matched patients who opted for PGD using fluorescence in situ hybridization (FISH) 
analysis. There were no differences in the LBR at the first trial (37.8\% vs 53.8\%, respectively), in the cumulative LBR ( $67.6 \%$ vs $65.4 \%$, respectively), and in the mean interval of months from genetic counseling to the pregnancy (12.4 vs 11.4, respectively). However, PGD significantly decreased the mean number of miscarriages $(0.22 \pm 0.42$ vs $0.58 \pm 0.78$, $P=0.012$ ) and significantly increased the number of twin pregnancies. ${ }^{105}$

Overall, cumulative LBRs seem to be comparable following IVF/PGD or expectant management in couples with RPL and balanced translocations. IVF/PGD decreases the rate of miscarriage and could shorten the time to the first live birth. It could also decrease the emotional stress and uncertainty associated with a positive pregnancy test. However, IVF/ PGD is an expensive procedure and carries some risk of complications, such as ovarian hyperstimulation syndrome. It could be in itself a source of significant emotional burden for the couple, because it offers no guarantees of healthy embryos or pregnancies, with many stimulation cycles sometimes needed. PGD could thus be considered beneficial for couples with high-risk translocations by reducing the risk of miscarriage and avoiding a child with an unbalanced form of the translocation, but for low-risk translocations, natural conception should be the preferred option. Couples with RPL due to a balanced translocation should have thorough genetic counseling to better assess their future risks, and then choose the option they believe is best for them.

\section{Workup}

It is not recommended to evaluate a couple following one miscarriage. ${ }^{106}$ However, whether to initiate a full workup after two of three miscarriages has long been debated. For years, it was recommended to wait for three miscarriages, but several studies have now shown that the risk of a future miscarriage after two successive losses (24\%-29\%) is similar to or slightly lower than the risk after three losses (31\%-33\%), and the findings are comparable. ${ }^{8,107}$ Therefore, it is acceptable to start a workup following two consecutive losses, especially in women aged $>35$ years. ${ }^{2,108}$

Evaluation starts with a complete history for both partners and information about previous pregnancies and miscarriages. A thorough gynecologic history should be obtained, as well as a family history of infertility or miscarriage. Both partners should also be questioned about the modifiable lifestyle factors, such a smoking, alcohol use, and nutritional habits. $2,7,106,108$

A full workup must be ordered following the initial visit to identify treatable causes. The exact definition of a "full workup" varies between the various international societies and the different recommendations, but it must be tailored according to the couple, taking into account several factors, such as the woman and her partner's age, the personal and family medical history, the couple's emotional state, as well and the center's technical platform, and the finances.

A blood workup should include a complete blood count, fasting serum glucose (or hemoglobin $\mathrm{A}_{1 \mathrm{c}}$ ) and prolactin level, serum TSH, as well as antibodies for APS (lupus anticoagulant, anticardiolipin antibodies, and anti- $\beta$ II glycoprotein I antibodies). Some recent studies suggest antiphosphatidylserine should also be included in the analysis, but it is not yet included in the recommendations. ${ }^{108}$ Testing for thyroid autoantibodies is only recommended in case of abnormal findings suggesting thyroid disease. Testing for inherited thrombophilias (FVL, PT G20210A, MTHFR, PCR, PSR, $\mathrm{AT}$ ) is not recommended unless there is a personal or a strong family history of thrombosis. ${ }^{2,7,108}$ However, several reports suggest that they are routinely ordered in clinical practice. ${ }^{51}$ A transvaginal three-dimensional ultrasound for the assessment of the uterine cavity and the antral follicle count should be performed. The uterine cavity should be further explored with a sonohysterography, a hysterosalpingography, or a hysteroscopy. Pelvic magnetic resonance imaging can be helpful in complicated cases of anatomic defects. Finally, karyotypes for both partners should also be ordered. . $^{2,108}$

For years, genetic evaluation of the POC was not routinely ordered because it was considered difficult and unreliable. Indeed, because it was done by routine karyotype analysis, it was associated with a risk of maternal cell contamination, a risk of false-negative results, and a risk of failed cell culture because of the presence of toxic cells and substances. However, the use of new techniques, such as single-nucleotide polymorphism microarrays and comparative genomic hybridization (CGH), resolved these issues and allowed for a 23-chromosome pair analysis. The genetic evaluation of the POC is nowadays considered easy and reproducible, and many referral centers for RPL currently start their evaluation of a couple with RPL with a POC karyotype. ${ }^{108}$ If euploid, a full RPL workup is ordered. If an unbalanced chromosomal translocation or inversion is found, a parental karyotype is ordered and PGD offered for future attempts. Finally, an aneuploidy in the POC confirms the diagnosis and no further tests are necessary. Some studies have reported such a strategy to be more cost-effective than the classic evaluation. ${ }^{109,110}$ However, if a POC karyotype is not available, a full RPL workup is ordered. , $7,108^{2}$ 


\section{Unexplained RPL (URPL)}

Even with a comprehensive workup, an etiology for RPL is identified in less than half of the couples. ${ }^{2,108}$ URPL is considered the diagnosis if a complete genetic, anatomic, endocrine, and immune evaluation was performed and returned as normal (Table 2).

URPL is associated with significant adverse psychological consequences for the couple. Besides the grief following each miscarriage, there is the anxiety and insecurity associated with each positive pregnancy test. However, couples with URPL should be informed that the chances for a future successful pregnancy could be as high as $50 \%-70 \%$ and depend mostly on maternal age and the number of previous losses. ${ }^{111,112}$ According to one study, women aged $<30$ years are estimated to have a $75 \%$ chance of live birth within 2 years, compared to $40 \%$ for women aged 40 years. Moreover, for women with three miscarriages, the chance of a future live birth within 2 years is $70 \%$, compared to $45 \%$ following six miscarriages. ${ }^{111}$ Another study found a cumulative incidence of live birth of $50 \%$ after 24 months, and a median time to a live birth of 102 weeks. ${ }^{113}$

\section{Genetic predisposition to URPL}

Several studies have reported a genetic predisposition to URPL, with an increased risk in siblings of patients with URPL. ${ }^{114,115}$ Various genetic association studies have been performed, and many candidate genes identified. A recent meta-analysis that included 428 case-control studies found an association for 21 variants in 13 genes. ${ }^{116}$ Most of the genes were involved in immune response, followed by coagulation, metabolism, and angiogenesis. However, all the associations were modest, and none reached strong epidemiologic credibility. ${ }^{116}$ Another meta-analysis using different criteria found significant associations with 53 genetic polymorphisms of 37 genes ${ }^{117}$ Interleukin genes are the most commonly associated with RPL, especially IL-1 $\beta$, IL-6, IL-10, and IL-18. ${ }^{116-118}$ Indeed, a successful pregnancy depends on immune balance, and interleukins secreted by immune cells play important roles in that balance at different stages of implantation. Variants of these genes alter the corresponding protein's expression levels and can therefore facilitate or hinder implantation. These preliminary results support the assumption of a genetic predisposition to RPL. However, there are several differences in the definitions and inclusion criteria used across the various reports. Therefore, guidelines for genetic association studies in RPL, as well as major genome-wide association studies, and studies including the male partner are needed to further define the role of genetic variants in RPL. Finally, studies focusing on the associations between maternal human leukocyte antigen (HLA) alleles (HLA class I [HLA-C2], HLA class II [DRB1, DQA1, DQB1 and DBP], HLA-E, HLA-G), as well as HLA sharing between couples and URPL have produced inconsistent results, ${ }^{119,120}$ and there is insufficient evidence to recommend management based on HLA phenotypes. ${ }^{2}$

Table 2 Etiologies of recurrent pregnancy loss, recommended tests for diagnosis, and treatment options

\begin{tabular}{|c|c|c|}
\hline Etiology & Tests for diagnosis & Treatment options \\
\hline \multirow[t]{3}{*}{ Uterine factor } & 3D ultrasonography, sonohysterography, & Hysteroscopic resection of septum \\
\hline & hysterosalpingography, hysteroscopy & Myomectomy, hysteroscopic removal of polyps \\
\hline & Magnetic resonance imaging & Adhesiolysis \\
\hline Antiphospholipid syndrome & $\mathrm{aCL}$, Anti- $\beta 2 \mathrm{GPI}$, lupus anticoagulant & Heparin + aspirin \\
\hline \multirow[t]{3}{*}{ Endocrine abnormality } & Thyroid-stimulating hormone & Levothyroxine \\
\hline & Prolactin & Bromocriptine \\
\hline & Fasting glucose or $\mathrm{HbA}_{\mathrm{lc}}$ & Diabetes control (weight loss, nutrition, metformin) \\
\hline \multirow[t]{2}{*}{ Genetic } & Karyotype of product of conception & Genetic counseling \\
\hline & Parental karyotype & Preimplantation genetic diagnosis for balanced translocation \\
\hline \multirow[t]{2}{*}{ Environmental factors } & Screen for smoking, drug use, excessive & Eliminate environmental toxins \\
\hline & alcohol and caffeine intake & \\
\hline Psychological & & Psychological support in a specialized setting \\
\hline \multirow[t]{3}{*}{ Unexplained } & & Progesterone supplementation (no consensus) \\
\hline & & Immunomodulating treatments (no consensus) \\
\hline & & Preimplantation genetic screening (no consensus) \\
\hline \multicolumn{3}{|l|}{ Other (no consensus) } \\
\hline Luteal phase deficiency & Mid-luteal progesterone, endometrial biopsy & Progesterone supplementation \\
\hline Chronic endometritis & Endometrial biopsy & Antibiotic treatment \\
\hline Other infections & Cultures & Appropriate treatment \\
\hline Male factor & DNA fragmentation test on sperm & Lifestyle modifications, multivitamins, donor sperm \\
\hline
\end{tabular}

Note: Anti- $\beta 2 \mathrm{GPI}$ : anti- $\beta 2$ glycoprotein-I.

Abbreviations: $\mathrm{aCL}$, anticardiolipin; 3D, three-dimensional. 


\section{Immune dysregulation and URPL}

Immune dysregulation has been proposed as a potential etiology in URPL. Indeed, maternal immune tolerance of the fetus is essential for normal implantation and pregnancy, and is characterized by an induction of regulatory $T$ cells and an anti-inflammatory Th-2 profile. Thus, a disruption of the normal CD4 T-helper cell (Th) and uterine natural killer (NK) activity, and a Th imbalance in the endometrium could lead to implantation failure and pregnancy loss. Immunomodulatory treatments have therefore been proposed for women with URPL. ${ }^{121}$

Asprin, LMWH, and a combination of the two have been used to treat URPL. However, well-designed RCTs have shown that aspirin alone, ${ }^{122,123}$ or LMWH alone, ${ }^{123,124}$ or the combination of the two ${ }^{125}$ did not improve LBR in women with URPL and are therefore not recommended.

Synthetic corticosteroids, because of their known immunosuppressive effect on Th and NK cells, have been explored as a potential treatment. Prednisolone effectively reduces the number of uterine NK cells in women with RPL and is the most widely used in this patient population. ${ }^{126}$ Some studies showed an improvement in LBR when prednisolone was combined with aspirin or $\mathrm{LMWH},{ }^{127,128}$ whereas others showed no effect. ${ }^{41}$ Moreover, the safety of corticosteroid treatment in the first trimester is still under scrutiny, with some studies showing an increased risk of prematurity, as well as maternal hypertension and diabetes. ${ }^{41,129}$ The interpretation of the available data has been made difficult by the presence of several confounding factors, concomitant drug use, and different definitions of RPL. Overall, administration of glucocorticoids in the absence of autoimmunity is not recommended in women with RPL because it does not improve implantation rates and is a potential risk to healthy pregnancy outcome. , $7,130,131^{-1}$

IVIg have also been used in women with URPL, but several trials failed to show any positive impact. ${ }^{132-134} \mathrm{In}$ the largest placebo-controlled trial that included 82 women with unexplained secondary RPL, LBRs were comparable between IVIg (54.8\%) and placebo (50\%). ${ }^{135} \mathrm{~A}$ recent meta-analysis of 11 randomized trials in women with URPL also showed no difference in LBR between IVIg and placebo (RR: 0.92, 95\% confidence interval [CI]: 0.75-1.12, $P=0.42) .{ }^{136}$ IVIg is therefore not recommended for women with URPL. ${ }^{2,7}$ Similar treatments, such as immunization using white blood cells from the partner, white blood cells from a third-party donor, or products derived from early embryos, failed to show any positive impact and should not be used. ${ }^{137}$
TNF- $\alpha$ is reportedly involved in fetal loss via thrombotic and inflammatory factors. TNF- $\alpha$ antagonists, such as adalimumab, have been used for URPL. A retrospective study of 75 pregnancies showed improved LBR when a combination of adalimumab and IVIg was added to anticoagulants compared to anticoagulants alone. ${ }^{138}$ However, no prospective studies are available, and there are still concerns over its safety during pregnancy. ${ }^{139}$

Intralipids are a fat emulsion used as parenteral nutrition that were shown to have immunomodulatory properties by in vitro and animal studies, and they act by inhibiting NK cell activity. ${ }^{140}$ Only one small, randomized trial showed comparable pregnancy rates to IVIg treatment, ${ }^{141}$ but more studies are needed for clinical evaluation of efficacy and safety.

Granulocyte colony-stimulating factor (G-CSF), a cytokine that stimulates neutrophilic granulocyte proliferation and differentiation, is produced by decidual cells, and studies show it has a positive impact on the trophoblast and antiabortive actions in animals. ${ }^{121}$ One RCT found that G-CSF administration significantly increased LBR in women with URPL compared to placebo ( $82.8 \%$ vs $48.5 \%, P=0.006$ ), without major side effects. ${ }^{142}$ Larger multicenter trials are needed before recommending G-CSF use in clinical practice.

\section{Sperm DNA fragmentation (SDF) and URPL}

Standard semen parameters do not seem to be associated with the risk of pregnancy loss. ${ }^{143}$ However, in vitro and in vivo studies have now shown that an elevated SDF negatively affects fertility, ${ }^{144}$ and it has been proposed as a cause of miscarriage. ${ }^{145}$ There are several methods to test SDF, the most commonly used being the terminal deoxynucleotidyl transferase dUTP nick end labeling assay, the sperm chromatin dispersion test, and the sperm chromatin structure assay. A meta-analysis of 16 cohort studies involving 2,969 couples found a significant increase in miscarriage in patients with high SDF. ${ }^{146}$ Two recent cohort studies found SDF, measured with sperm chromatin dispersion test, to be significantly higher in couples in the URPL group compared to a control group of fertile men. ${ }^{147,148}$ Therefore, it seems reasonable to offer SDF testing to couples with otherwise URPL. Besides advanced paternal age, many environmental factors, such as cigarette smoking, obesity, exogenous heat, and exposure to toxins, have been associated with increased SDF. Even though SDF is still not recommended by many societies as part of the workup for RPL, ${ }^{2,7}$ ordering the test could be useful and could help strengthen the decision to pursue lifestyle modifications. ${ }^{149}$ 


\section{Progesterone supplementation for URPL}

Progesterone supplementation has been proposed as treatment for URPL. Different preparations, routes, doses, and durations have been reported. A meta-analysis of 2,158 women from 14 trials found that progesterone supplementation was ineffective for preventing sporadic miscarriages, but data from four trials in women with three or more consecutive miscarriages showed that progesterone significantly reduced miscarriage rates compared to placebo or no treatment (odds ratio: $0.39 ; 95 \%$ CI: $0.21-0.72) .{ }^{150}$ The quality of the four trials was, however, considered poor. A recent multicenter, double-blind, placebo-controlled trial randomly assigned 836 women with URPL to receive either vaginal micronized progesterone (400 mg, twice daily) or placebo following a positive pregnancy test and found no differences in LBR $(65.8 \%$ vs $63.3 \%$, respectively). ${ }^{151}$ More recently, a meta-analysis of 10 RCTs including 1,586 women with URPL found a significantly lower risk of recurrent miscarriage (RR: $0.72,95 \% \mathrm{CI}$ : 0.53-0.97) and a higher chance of live birth (RR: 1.07, 95\% CI: 1.02-1.15) following supplementation with progesterone. ${ }^{152}$ However, only synthetic progestins were found to be beneficial, whereas natural and micronized progesterone had no impact. ${ }^{152}$ Moreover, a more recent observational cohort study found that vaginal micronized progesterone, started 3 days after the urinary LH surge, significantly improved pregnancy rates in women with URPL. ${ }^{153}$ There are several physiological and pharmacological differences between natural and synthetic progestogens that might explain the differences in results. For instance, synthetic intramuscular progestogens result in a higher plasma concentration for a significantly longer time. ${ }^{154}$ Overall, progesterone administration seems to be beneficial for women with URPL. However, based on the current data, it is difficult to recommend when to initiate treatment and which specific preparation route and dose to use. Further randomized trials are needed to fully answer the question.

\section{PGS for URPL}

PGS has recently been proposed as an option for couples with URPL. PGS was first introduced in 1993 to select euploid embryos in infertile couples undergoing IVF, in order to transfer the embryos with the highest developmental potential, thus improving implantation rates and decreasing miscarriage rates. ${ }^{155}$ PGS involves the analysis of all 23 chromosome pairs, with several molecular techniques used across the years, including FISH, CGH, array CGH (aCGH), single-nucleotide polymorphism array, quantitative or real-time polymerase chain reaction, and next-generation sequencing, also known as massive parallel sequencing. The characteristics of each of these methods are beyond the scope of this review, but there are several key differences and the results vary significantly. In brief, FISH was the first technique used, ${ }^{155}$ and it allowed the evaluation of a limited number of chromosomes (5-10) on blastomeres removed from cleavage stage embryos. Therefore, only the chromosomes thought to be more likely involved in aneuploidy were analyzed. However, most RCTs failed to show any benefit of PGS using FISH, and some even reported a deleterious effect. ${ }^{156}$ Many reasons were identified. First of all, as many studies later showed, aneuploidy is equally distributed between all 23 chromosomes; thus, many aneuploid errors were unnoticed in embryos considered euploid. Another problem is embryo mosaicism, which is estimated to be as high at $50 \%$ at cleavage stage; the cells biopsied were thus not necessarily representative of the ploidy status of the embryo. Finally, embryo biopsy at the cleavage stage is traumatic and has a deleterious impact on its development potential. ${ }^{156-159}$ Newer techniques removed most of these drawbacks: The biopsy is now performed at the blastocyst stage, where the mosaicism is significantly lower $(3 \%-5 \%)$; trophectoderm cells are removed and the biopsy is less detrimental to embryo development; and all 23 chromosome pairs are analyzed. However, all these techniques are not equally efficient, and although they can all detect whole chromosome aneuploidy, they differ in their abilities to identify mosaicism, as well as other structural abnormalities, and their lowest detection thresholds. ${ }^{156-159}$ It is worth noting that PGS can also be performed on a polar body biopsy, thus avoiding the need for extended in vitro embryo culture and eliminating the problem of mosaicism and the potential detrimental effect of the embryo biopsy. It also leaves more time to complete the chromosome studies. ${ }^{158,159}$ Its main pitfall is that it tests only maternal aneuploidies, but this drawback is lessened by the fact that $>90 \%$ of aneuploidies at birth are of maternal origin. ${ }^{158,159}$ However, most centers nowadays use trophectoderm biopsy at the blastocyst stage, and only methods that allow the assessment of the ploidy status of all 23 chromosome pairs are recommended for comprehensive chromosome screening. ${ }^{158,159}$ However, experience in extended embryo culture and biopsy is required, as well as a good genetic platform, and an efficient vitrification program. The choice between the different platforms should take into account the clinical background, the couple's needs, the cost, and the availability and expertise of the laboratories performing the IVF cycle and the genetic screening. ${ }^{158,159}$ 
Three $\mathrm{RCTs}^{160-162}$ and a recent meta-analysis that included these RCTs ${ }^{163}$ showed that the transfer of euploid embryos following PGS significantly improves pregnancy rates. However, the RCTs included only young patients with normal ovarian reserve and good prognosis, and caution must be taken before extrapolating these results to other patient populations. Indeed, no RCTs have looked at the beneficial impact of PGS in couples with RPL and normal karyotypes. ${ }^{156,159,163,164}$ However, despite the lack of conclusive evidence, a recent survey comprising of PGS experts from Europe and the United States showed that repeated miscarriages were, with repeated implantation failure, the most frequent indication for PGS in their respective centers. ${ }^{165}$

Several noninvasive technologies are currently being developed for PGS, such as tanscriptomics, metabolomics, epigenomics, and mitochondrial function tests. With the continuous technological developments, the improvements in efficiency, the increasing availability, and the cost reduction, it is likely that PGS will help improving IVF efficiency. However, it remains to be seen whether that is the case for couples with URPL. Many trials are currently under way in order to select the patient population most likely to benefit from PGS. ${ }^{158,159,165}$

\section{Conclusion}

RPL is an important reproductive health issue. Various etiologies have been identified over the years and successful therapeutic strategies implemented. A full workup can be initiated following two consecutive losses to identify treatable causes that include uterine abnormalities, APS, endocrine diseases, and balanced translocations. Lifestyle modifications should also be implemented to improve reproductive prognosis. However, almost half of the cases remain unexplained, for which various treatments are continuously being developed. Regardless of the cause, a thorough follow-up with an important psychological support can help most couples achieve a successful live birth.

\section{Disclosure}

The authors report no conflicts of interest in this work.

\section{References}

1. Zegers-Hochschild F, Adamson GD, de Mouzon J, et al. International Committee for Monitoring Assisted Reproductive Technology; World Health Organization. International Committee for Monitoring Assisted Reproductive Technology (ICMART) and the World Health Organization (WHO) revised glossary of ART terminology, 2009. Fertil Steril. 2009;92(5):1520-1524.
2. Practice Committee of the American Society for Reproductive Medicine. Evaluation and treatment of recurrent pregnancy loss: a committee opinion. Fertil Steril. 2012;98(5):1103-1111.

3. Wilcox AJ, Weinberg CR, O'Connor JF, et al. Incidence of early loss of pregnancy. N Eng J Med. 1988;319(4):189-194.

4. Kolte AM, Bernardi LA, Christiansen OB, et al; ESHRE Special Interest Group, Early Pregnancy. Terminology for pregnancy loss prior to viability: a consensus statement from the ESHRE early pregnancy special interest group. Hum Reprod. 2015;30(3):495-498.

5. Silver RM, Branch DW, Goldenberg R, Iams JD, Klebanoff MA. Nomenclature for pregnancy outcomes: time for a change. Obstet Gynecol. 2011;118(6):1402-1408.

6. Jauniaux E, Farquharson RG, Christiansen OB, Exalto N. Evidencebased guidelines for the investigation and medical treatment of recurrent miscarriage. Hum Reprod. 2006;21(9):2216-2222.

7. Royal College of Obstetricians and Gynaecologists, Scientific Advisory Committee, Guideline No. 17. The Investigation and treatment of couples with recurrent miscarriage, 2011. Available from: http:// www.rcog.org.uk/womens-health/clinical-guidance/investigationand-treatmentcouples-recurrent-miscarriage-green-top-. Accessed January 10, 2017.

8. Jaslow CR, Carney JL, Kutteh WH. Diagnostic factors identified in 1020 women with two versus three or more recurrent pregnancy losses. Fertil Steril. 2010;93(4):1234-1243.

9. Deans R, Abbott J. Review of intrauterine adhesions. J Minim Invasive Gynecol. 2010;17(5):555-569.

10. Munro MG, Critchley HO, Broder MS, Fraser IS; FIGO Working Group on Menstrual Disorders. FIGO classification system (PALMCOEIN) for causes of abnormal uterine bleeding in nongravid women of reproductive age. Int J Gynaecol Obstet. 2011;113(1):3-13.

11. Sinclair DC, Mastroyannis A, Taylor HS. Leiomyoma simultaneously impair endometrial BMP-2-mediated decidualization and anticoagulant expression through secretion of TGF-beta3. J Clin Endocrinol Metab. 2011;96(2):412-421.

12. Jaslow C. Uterine factors. Obstet Gynecol Clin North Am. 2014;41(1): $57-86$.

13. Salim S, Won H, Nesbitt-Hawes E, Campbell N, Abbott J. Diagnosis and management of endometrial polyps: a critical review of the literature. J Minim Invasive Gynecol. 2011;18(5):569-581.

14. The American Fertility Society classifications of adnexal adhesions, distal tubal occlusion, tubal occlusion secondary to tubal ligation, tubal pregnancies, Müllerian anomalies and intrauterine adhesions. Fertil Steril. 1988;49(6):944-955.

15. Grimbizis GF, Gordts S, Di Spiezio Sardo A, et al. The ESHRE/ESGE consensus on the classification of female genital tract congenital anomalies. Hum Reprod. 2013;28(8):2032-2044.

16. Grimbizis GF, Camus M, Tarlatzis BC, Bontis JN, Devroey P. Clinical implications of uterine malformations and hysteroscopic treatment results. Hum Reprod Update. 2001;7(2):161-174.

17. Valle RF, Ekpo GE. Hysteroscopic metroplasty for the septate uterus: review and meta-analysis. J Minim Invasive Gynecol. 2013;20(1): $22-42$.

18. Alborzi S, Asadi N, Zolghadri J, Alborzi S, Alborzi M. Laparoscopic metroplasty in bicornuate and didelphic uteri. Fertil Steril. 2009; 92(1):352-355.

19. Brucker SY, Rall K, Campo R, Oppelt P, Isaacson K. Treatment of congenital malformations. Semin Reprod Med. 2011;29(2):101-112.

20. Kitaya K. Prevalence of chronic endometritis in recurrent miscarriages. Fertil Steril. 2011;95(3):1156-1158.

21. McQueen DB, Perfetto CO, Hazard FK, Lathi RB. Pregnancy outcomes in women with chronic endometritis and recurrent pregnancy loss. Fertil Steril. 2015;104(4):927-931.

22. Bouet PE, El Hachem H, Monceau E, Gariépy G, Kadoch IJ, Sylvestre C. Chronic endometritis in women with recurrent pregnancy loss and recurrent implantation failure: prevalence and role of office hysteroscopy and immunohistochemistry in diagnosis. Fertil Steril. 2016;105(1): $106-110$. 
23. Giakoumelou S, Wheelhouse N, Cuschieri K, Entrican G, Howie SE, Horne AW. The role of infection in miscarriage. Hum Reprod Update. 2016;22(1):116-133.

24. Miyakis S, Lockshin MD, Atsumi T, et al. International consensus statement on an update of the classification criteria for definite antiphospholipid syndrome (APS). J Thromb Haemost. 2006;4(2):295-306.

25. Andreoli L, Chighizola CB, Banzato A, Pons-Estel GJ, Ramire de Jesus G, Erkan D. The estimated frequency of antiphospholipid antibodies in patients with pregnancy morbidity, stroke, myocardial infarction, and deep vein thrombosis. Arthritis Care Res (Hoboken). 2013; 65(11):1869-1873.

26. de Jesus GR, Agmon-Levin N, Andrade CA, et al. 14th International Congress on Antiphospholipid Antibodies Task Force report on obstetric antiphospholipid syndrome. Autoimmun Rev. 2014;13(8):795-813.

27. Opartrny L, David M, Kahn SR, Shrier I, Rey E. Association between antiphospholipid antibodies and recurrent fetal loss in women without autoimmune disease: a metaanalysis. J Rheumatol. 2006;33(11):2214-2221.

28. Di Simone N, Meroni PL, de Papa N, et al. Antiphospholipid antibodies affect trophoblast gonadotropin secretion and invasiveness by binding directly and through adhered beta2-glycoprotein I. Arthritis Rheum. 2000;43(1):140-150.

29. Di Simone N, Castellani R, Caliandro D, Caruso A. Monoclonal anti-annexin $\mathrm{V}$ antibody inhibits trophoblast gonadotropin secretion and induces syncytiotrophoblast apoptosis. Biol Reprod. 2001;65(6): 1766-1770.

30. Meroni PL, Borghi MO, Raschi E, Tedesco F. Pathogenesis of antiphospholipid syndrome: understanding the antibodies. Nat Rev Rheumatol. 2011;7(6):330-339.

31. Chaleur C, Galanaud JP, Alonso S, et al. Observational study of pregnant women with a previous spontaneous abortion before the 10th gestation week with and without antiphospholipid antibodies. J Thromb Haemost. 2010;8(4):699-706.

32. Ruffatti A, Tonello M, Cavazzana A, Bagatella P, Pengo V. Laboratory classification categories and pregnancy outcome in patients with primary antiphospholipid syndrome prescribed antithrombotic therapy. Thromb Res. 2009;123(3):482-487.

33. Kutteh WH, Hinote CD. Antiphospholipid antibody syndrome. Obstet Gynecol Clin North Am. 2014;41(1):113-132.

34. Di Simone N, Di Nicuolo F, Sarguinetti M, et al. Low-molecular weight heparin induces in vitro trophoblast invasiveness: role of matrix metalloproteinases and tissue inhibitors. Placenta. 2007;28(4):298-304.

35. Brezina PR, Kutteh WH. Classic and cutting-edge strategies for the management of early pregnancy loss. Obstet Gynecol Clin North Am. 2014;41(1):1-18.

36. Kutteh WH. Antiphospholipid antibody-associated recurrent pregnancy loss: treatment with heparin and low dose aspirin is superior to low dose aspirin alone. Am J Obstet Gynecol. 1996;174(5):1584-1589.

37. Empson M, Lassere M, Craig J, Scott J. Prevention of recurrent miscarriage for women with antiphospholipid antibody or lupus anticoagulant. Cochrane Database Syst Rev. 2005;(2):CD002859.

38. Hoppe B, Burmester GR, Dorner T. Heparin or aspirin or both in the treatment of recurrent abortions in women with antiphospholipid antibody (syndrome). Curr Opin Rheumatol. 2011;23(3):299-304.

39. Stephenson MD, Ballem PJ, Tsang P, et al. Treatment of antiphospholipid antibody syndrome (APS) in pregnancy: a randomized pilot trial comparing low molecular weight heparin to unfractionated heparin. J Obstet Gynaecol Can. 2004;26(8):729-734.

40. Noble LS, Kutteh WH, Lashey N, Franklin RD, Herrada J. Antiphospholipid antibodies associated with recurrent pregnancy loss: prospective, multicenter, controlled pilot study comparing treatment with low-molecular-weight heparin versus unfractionated heparin. Fertil Steril. 2005;83(3):684-690.

41. Laskin CA, Bombardier C, Hannah ME, et al. Prednisone and aspirin in women with autoantibodies and unexplained recurrent fetal loss. N Engl J Med. 1997;337(3):148-153.

42. Stevens SM, Woller SC, Bauer KA, et al. Guidance for the evaluation and treatment of hereditary and acquired thrombophilia. $J$ Thromb Thrombolysis. 2016;41(1):154-164.
43. American College of Obstetricians and Gynecologists Women's Health Care Physicians. ACOG Practice Bulletin No. 138: inherited thrombophilias in pregnancy. Obstet Gynecol. 2013;122(3):706-717.

44. Rey E, Kahn SR, David M, Shrier I. Thrombophilic disorders and fetal loss: a meta-analysis. Lancet. 2003;361(9361):901-908.

45. Nelen WL, Blom HJ, Steegers EA, den Heijer M, Eskes TK. Hyperhomocysteinemia and recurrent early pregnancy loss: a meta-analysis. Fertil Steril. 2000;74(6):1196-1199.

46. Lissalde-Lavigne G, Fabbro-Peray P, Cochery-Nouvellon E, et al. Factor V Leiden and prothrombin G20210A polymorphisms as risk factors for miscarriage during a first intended pregnancy: the matched case-control "NOHA first" study. J Thromb Haemost. 2005;3(10):2178-2184.

47. Dizon-Townson D, Miller C, Sibai B, et al. The relationship of the factor V Leiden mutation and pregnancy outcomes for mother and fetus. National Institute of Child Health and Human Development Maternal-Fetal Medicine Units Network. Obstet Gynecol. 2005;106(3):517-524.

48. Silver RM, Zhao Y, Spong CY, et al. Prothrombin gene G20210A mutation and obstetric complications. Eunice Kennedy Shriver National Institute of Child Health and Human Development Maternal-Fetal Medicine Units (NICHD MFMU) Network. Obstet Gynecol. 2010; 115(1):14-20

49. Skeith L, Carrier M, Kaaja R, et al A meta-analysis of low-molecularweight heparin to prevent pregnancy loss in women with inherited thrombophilia. Blood. 2016;127(13):1650-1655.

50. de Jong PG, Kaandorp S, Di Nisio M, Goddijn M, Middeldorp S. Aspirin and/or heparin for women with unexplained recurrent miscarriage with or without inherited thrombophilia. Cochrane Database Syst Rev. 2014;(7):CD004734.

51. Davenport WB, Kutteh WH. Inherited thrombophilias and adverse pregnancy outcomes: a review of screening patterns and recommendations. Obstet Gynecol Clin North Am. 2014;41(1):133-144.

52. Bussen S, Sütterlin M, Steck T. Endocrine abnormalities during the follicular phase in women with recurrent spontaneous abortion. Hum Reprod. 1999;14(1):18-20.

53. Hirahara F, Andoh N, Sawai K, Hirabuki T, Uemura T, Minaguchi H. Hyperprolactinemic recurrent miscarriage and results of randomized bromocriptine treatment trials. Fertil Steril. 1998;70(2):246-252.

54. Chen H, Fu J, Huang W. Dopamine agonists for preventing future miscarriage in women with idiopathic hyperprolactinemia and recurrent miscarriage history. Cochrane Database Syst Rev. 2016;7:CD008883.

55. Cleary-Goldman J, Malone FD, Lambert-Messerlian G, et al. Maternal thyroid hypofunction and pregnancy outcome. Obstet Gynecol. 2008; 112(1):85-92.

56. Liu H, Shan Z, Li C, et al. Maternal subclinical hypothyroidism, thyroid autoimmunity, and the risk of miscarriage: a prospective cohort study. Thyroid. 2014;24(11):1642-1649.

57. Benhadi N, Wiersinga WM, Reitsma JB, et al. Higher maternal TSH levels in pregnancy are associated with increased risk for miscarriage, fetal or neonatal death. Eur J Endocrinol. 2009;160(6):985-991.

58. De Groot L, Abalovich M, Alexander EK, et al. Management of thyroid dysfunction during pregnancy and postpartum: an Endocrine Society Clinical Practice Guideline. J Clin Endocrinol Metab. 2012; 97(8):2543-2565.

59. Bernardi LA, Cohen RN, Stephenson MD. Impact of subclinical hypothyroidism in women with recurrent early pregnancy loss. Fertil Steril. 2013;100(5):1326-1331.

60. van Dijk MM, Vissenberg R, Bisschop PH, et al. Is subclinical hypothyroidism associated with lower live birth rates in women who have experienced unexplained recurrent miscarriage? Reprod Biomed Online. 2016;33(6):745-751

61. De Carolis C, Greco E, Guarino MD, et al. Anti-thyroid antibodies and antiphospholipid syndrome: evidence of reduced fecundity and of poor pregnancy outcome in recurrent spontaneous aborters. Am J Reprod Immunol. 2014;52(4):263-266.

62. van den Boogaard E, Vissenberg R, Land JA, et al. Significance of (sub)clinical thyroid dysfunction and thyroid autoimmunity before conception and in early pregnancy: a systematic review. Hum Reprod Update. 2011;17(5):605-619. 
63. Iravani AT, Saeedi MM, Pakravesh J, Hamidi S, Abbasi M. Thyroid autoimmunity and recurrent spontaneous abortion in Iran: a case-control study. Endocr Pract. 2008;14(4):458-464.

64. Reid SM, Middleton P, Cossich MC, Crowther CA, Bain E. Interventions for clinical and subclinical hypothyroidism pre-pregnancy and during pregnancy. Cochrane Database Syst Rev. 2013;5:CD007752.

65. Glueck CJ, Wang P, Bornovali S, et al. Polycystic ovary syndrome, the G1691A factor V Leiden mutation, and plasminogen activator inhibitor activity: association with recurrent pregancy loss. Metabolism. 2003; 52(12):1627-1632.

66. Feng Y, Yang H. Metformin - a potentially effective drug for gestational diabetes mellitus: a systematic review and meta-analysis. J Matern Fetal Neonatal Med. 2016:1-8.

67. Glueck CJ, Phillips H, Cameron D, et al. Continuing metformin throughout pregnancy in women with polycystic ovary syndrome appears to safely reduce first trimester spontaneous abortion: a pilot study. Fertil Steril. 2001;75(1):46-52.

68. Jakubowicz DJ, Iuorno MJ, Jakubowicz S, et al. Effects of metformin on early pregnancy loss in polycystic ovary syndrome. J Clin Endocrinol Metab. 2002;87(2):524-529.

69. Zolghadri J, Tavana Z, Kazerooni T, et al. Relationship between abnormal glucose tolerance test and history of previous recurrent miscarriages, and beneficial effects of metformin in these patients: a prospective clinical study. Fertil Steril. 2008;90(3):727-730.

70. Bordewijk EM, Nahuis M, Costello MF, et al. Metformin during ovulation induction with gonadotrophins followed by timed intercourse or intrauterine insemination for subfertility associated with polycystic ovary syndrome. Cochrane Database Syst Rev. 2017;1: CD009090.

71. Jovanovic L, Knopp H, Kim H, et al. Elevated pregnancy losses at high and low extremes of maternal glucose in early normal and diabetic pregnancies: evidence for a protective adaptation in diabetes. Diabetes Care. 2005;28(5):1113-1117.

72. Jones GE. Some newer aspects of management of infertility. J Am Med Assoc. 1949;141(16):1123-1129.

73. Jones GS. The luteal phase defect. Fertil Steril. 1976;27(4):351-356.

74. Li TC, Spuijbroek MD, Tuckerman E, et al. Endocrinological and endometrial factors in recurrent miscarriage. BJOG. 2000;107(12): 1471-1479.

75. Ke RW. Endocrine basis for recurrent pregnancy loss. Obstet Gynecol Clin North Am. 2014;41(1):103-112.

76. American Society for Reproductive Medicine. Clinical relevance of luteal phase deficiency. Fertil Steril. 2012;98(5):1112-1117.

77. Practice Committee of the American Society for Reproductive Medicine. Progesterone supplementation during the luteal phase and in early pregnancy in the treatment of infertility: an educational bulletin. Fertil Steril. 2008;89(4):789-792.

78. Fox C, Azores-Gococo D, Swart L, et al. Luteal phase HCG support for unexplained recurrent pregnancy loss - a low hanging fruit? Reprod Biomed Online. 2017;34(3):319-324.

79. Metwally M, Saravelos SH, Ledger WL, Li TC. Body mass index and risk of miscarriage in women with recurrent miscarriage. Fertil Steril. 2010;94(1):290-295.

80. Moussa HN, Alrais MA, Leon MG, Abbas EL, Sibai BM. Obesity epidemic: impact from preconception to postpartum. Future Sci OA. 2016;2(3):FSO137.

81. Lassi ZS, Imam AM, Dean SV, Bhutta ZA. Preconception care: caffeine, smoking, alcohol, drugs and other environmental chemical/radiation exposure. Reprod Health. 2014;11(Suppl 3):S6.

82. Tolstrup JS, Kjaer SK, Munk C, et al. Does caffeine and alcohol intake before pregnancy predict the occurrence of spontaneous abortion? Hum Reprod. 2003;18(12):2704-2710.

83. Ness RB, Grisso JA, Hirshinger N, et al. Cocaine and tobacco use and the risk of spontaneous abortion. N Engl J Med. 1999;340(5):333-339.

84. Gaskins AJ, Rich-Edwards JW, Williams PL, Toth TL, Missmer SA, Chavarro JE. Prepregnancy low to moderate alcohol intake is not associated with risk of spontaneous abortion or stillbirth. J Nutr. Epub 2016 Mar 9.
85. Kolte AM, Olsen LR, Mikkelsen EM, Christiansen OB, Nielsen HS. Depression and emotional stress is highly prevalent among women with recurrent pregnancy loss. Hum Reprod. 2015;30(4):777-782.

86. Sugiura-Ogasawara M, Furukawa TA, Nakano Y, Hori S, Aoki K, Kitamura T. Depression as a potential causal factor in subsequent miscarriage in recurrent spontaneous aborters. Hum Reprod. 2002;17(10): 2580-2584

87. Brigham SA, Conlon C, Farquharson RG. A longitudinal study of pregnancy outcome following idiopathic recurrent miscarriage. Hum Reprod. 1999;14(11):2868-2871.

88. Stray-Pedersen B, Stray-Pedersen S. Recurrent abortion: the role of psychotherapy. In: Beard RW, Ship F, editors. Early Pregnancy Loss: Mechanisms and Treatment. New York, NY: Springer-Verlag; 1988: $433-440$

89. Sugiura-Ogasawara M, Ozaki Y, Katano K, Suzumori N, Kitaori T, Mizutani E. Abnormal embryonic karyotype is the most frequent cause of recurrent miscarriage. Hum Reprod. 2012;27(8):2297-2303.

90. Werner M, Reh A, Grifo J, Perle MA. Characteristics of chromosomal abnormalities diagnosed after spontaneous abortions in an infertile population. J Assist Reprod Genet. 2012;29(8):817-820.

91. De Braekeleer M, Dao TN. Cytogenetic studies in couples experiencing repeated pregnancy losses. Hum Reprod. 1990;5(5):519-528.

92. Laurino MY, Bennett RL, Saraiya DS, et al. Genetic evaluation and counseling of couples with recurrent miscarriage: recommendations of the National Society of Genetic Counselors. J Genet Couns. 2005;14(3): 165-181.

93. Stephenson MD, Sierra S. Reproductive outcomes in recurrent pregnancy loss associated with a parental carrier of a structural chromosome rearrangement. Hum Reprod. 2006;21(4):1076-1082.

94. Carp H, Guetta E, Dorf H, Soriano D, Barkai G, Schiff E. Embryonic karyotype in recurrent miscarriage with parental karyotypic aberrations. Fertil Steril. 2006;85(2):446-450.

95. De Rycke M, Belva F, Goossens V, et al. ESHRE PGD Consortium data collection XIII: cycles from January to December 2010 with pregnancy follow-up to October 2011. Hum Reprod. 2015;30(8): 1763-1789.

96. Ogasawara M, Aoki K, Okada S, Suzumori K. Embryonic karyotype of abortuses in relation to the number of previous miscarriages. Fertil Steril. 2000;73(2):300-304.

97. Stephenson MD, Awartani KA, Robinson WP. Cytogenetic analysis of miscarriages from couples with recurrent miscarriage: a case-control study. Hum Reprod. 2002;17(2):446-451.

98. Brezina PR, Kutteh WH. Clinical applications of preimplantation genetic testing. BMJ. 2015;350:g7611

99. Hirshfeld-Cytron J, Sugiura-Ogasawara M, Stephenson MD. Management of recurrent pregnancy loss associated with a parental carrier of a reciprocal translocation: a systematic review. Sem Reprod Med. 2011;29(6):470-481.

100. Franssen MT, Korevaar JC, van der Veen F, Leschot NJ, Bossuyt PM, Goddijn M. Reproductive outcome after chromosome analysis in couples with two or more miscarriages: index-control study. BMJ. 2006;332(7544):759-763.

101. Keymolen K, Staessen C, Verpoest W, Liebaers I, Bonduelle M. Preimplantation genetic diagnosis in female and male carriers of reciprocal translocations: clinical outcome until delivery of 312 cycles. Eur J Hum Genet. 2012;20(4):376-380.

102. Fischer J, Colls P, Escudero T, Munne S. Preimplantation genetic diagnosis (PGD) improves pregnancy outcome for translocation carriers with a history of recurrent losses. Fertil Steril. 2010;94(1) 283-289.

103. Scriven PN, Flinter FA, Khalaf Y, Lashwood A, Mackie Ogilvie C Benefits and drawbacks of preimplantation genetic diagnosis (PGD) for reciprocal translocations: lessons from a prospective cohort study. Eur J Hum Genet. 2013;21(10):1035-1041.

104. Franssen MT, Musters AM, van der Veen F, et al. Reproductive outcome after PGD in couples with recurrent miscarriage carrying a structural chromosome abnormality: a systematic review. Hum Reprod Update. 2011;17(4):467-475 
105. Ikuma S, Sato T, Sugiura-Ogasawara M, Nagayoshi M, Tanaka A, Takeda S. Preimplantation genetic diagnosis and natural conception: a comparison of live birth rates in patients with recurrent pregnancy loss associated with translocation. PLOS ONE. 2015;10(6):e0129958.

106. Committee on Practice Bulletins - Gynecology. The American College of Obstetricians and Gynecologists Practice Bulletin no. 150. Early pregnancy loss. Obstet Gynecol. 2015;125(5):1258-1267.

107. Stirrat GM. Recurrent miscarriage. Lancet. 1990;336(8716): 673-675.

108. Kutteh WH. Novel strategies for the management of recurrent pregnancy loss. Semin Reprod Med. 2015;33(3):161-168.

109. Bernardi LA, Plunkett BA, Stephenson MD. Is chromosome testing of the second miscarriage cost saving? A decision analysis of selective versus universal recurrent pregnancy loss evaluation. Fertil Steril. 2012;98(1):156-161.

110. Foyouzi N, Cedars MI, Huddleston HG. Cost-effectiveness of cytogenetic evaluation of products of conception in the patient with a second pregnancy loss. Fertil Steril. 2012;98(1):151-155.

111. Lund M, Kamper-Jørgensen M, Nielsen HS, Lidegaard Ø, Andersen AM, Christiansen OB. Prognosis for live birth in women with recurrent miscarriage: what is the best measure of success? Obstet Gynecol. 2012;119(1):37-43.

112. Kling C, Magez J, Hedderich J, von Otte S, Kabelitz D. Two-year outcome after recurrent first trimester miscarriages: prognostic value of the past obstetric history. Arch Gynecol Obstet. 2016;293(5): 1113-1123.

113. Kaandorp SP, van Mens TE, Middeldorp S, et al. Time to conception and time to live birth in women with unexplained recurrent miscarriage. Hum Reprod. 2014;29(6):1146-1152.

114. Christiansen OB, Mathiesen O, Lauritsen JG, Grunnet N. Idiopathic recurrent spontaneous abortion. Evidence of a familial predisposition. Acta Obstet Gynecol Scand. 1990;69(7-8):597-601.

115. Kolte AM, Nielsen HS, Moltke I, et al. A genome-wide scan in affected sibling pairs with idiopathic recurrent miscarriage suggests genetic linkage. Mol Hum Reprod. 2011;17(6):379-385.

116. Pereza N, Ostojić S, Kapović M, Peterlin B. Systematic review and meta-analysis of genetic association studies in idiopathic recurrent spontaneous abortion. Fertil Steril. 2017;107(1):150-159.e2.

117. Shi X, Xie X, Jia Y, Li S. Maternal genetic polymorphisms and unexplained recurrent miscarriage: a systematic review and meta-analysis. Clin Genet. 2017;91(2):265-284.

118. Zhang M, Xu J, Bao X, et al. Association between genetic polymorphisms in interleukin genes and recurrent pregnancy loss - a systematic review and meta-analysis. PLoS ONE. 2017;12(1):e0169891.

119. Fan W, Li S, Huang Z, Chen Q. Relationship between HLA-G polymorphism and susceptibility to recurrent miscarriage: a meta-analysis of non-family-based studies. J Assist Reprod Genet. 2014;31(2): 173-184.

120. Meuleman T, Lashley LE, Dekkers OM, van Lith JM, Claas FH, Bloemenkamp KW. HLA associations and HLA sharing in recurrent miscarriage: a systematic review and meta-analysis. Hum Immunol. 2015;76(5):362-373.

121. Mekinian A, Cohen J, Alijotas-Reig J, et al. Unexplained recurrent miscarriage and recurrent implantation failure: is there a place for immunomodulation? Am J Reprod Immunol. 2016;76(1):8-28.

122. Rai R, Backos M, Baxter N, Chilcott I, Regan L. Recurrent miscarriagean aspirin a day? Hum Reprod. 2000;15(10):2220-2223.

123. Schleussner E, Kamin G, Seliger G, et al. Low-molecular-weight heparin for women with unexplained recurrent pregnancy loss: a multicenter trial with a minimization randomization scheme. Ann Intern Med. 2015;162(9):601-609.

124. Pasquier E, de Saint Martin L, Bohec C, et al. Enoxaparin for prevention of unexplained recurrent miscarriage: a multicenter randomized doubleblind placebo-controlled trial. Blood. 2015;125(14):2200-2205.

125. Kaandorp SP, Goddijn M, van der Post JA, et al. Aspirin plus heparin or aspirin alone in women with recurrent miscarriage. $N$ Engl J Med. 2010;362(17):1586-1596.
126. Quenby S, Kalumbi C, Bates M, Farquharson R, Vince G. Prednisolone reduces preconceptual endometrial natural killer cells in women with recurrent miscarriage. Fertil Steril. 2005;84(4):980-984.

127. Tempfer CB, Kurz C, Bentz EK, et al. A combination treatment of prednisone, aspirin, folate, and progesterone in women with idiopathic recurrent miscarriage: a matched-pair study. Fertil Steril. 2006; 86(1):145-148.

128. Gomaa MF, Elkholy AG, El-Said MM, Abdel-Salam NE. Combined oral prednisolone and heparin versus heparin: the effect on peripheral NK cells and clinical outcome in patients with unexplained recurrent miscarriage. A double-blind placebo randomized controlled trial. Arch Gynecol Obstet. 2014;290(4):757-762.

129. Gur C, Diav-Citrin O, Shechtman S, Arnon J, Ornoy A. Pregnancy outcome after first trimester exposure to corticosteroids: a prospective controlled study. Reprod Toxicol. 2004;18(1):93-101.

130. Robertson SA, Jin M, Yu D, et al. Corticosteroid therapy in assisted reproduction - immune suppression is a faulty premise. Hum Reprod. 2016;31(10):2164-2173.

131. Kemp MW, Newnham JP, Challis JG, Jobe AH, Stock SJ. The clinical use of corticosteroids in pregnancy. Hum Reprod Update. 2016; 22(2):240-259.

132. Perino A, Vassiliadis A, Vucetich A, et al. Short-term therapy for recurrent abortion using intravenous immunoglobulins: results of a double-blind placebo-controlled Italian study. Hum Reprod. 1997; 12(11):2388-2392.

133. Jablonowska B, Selbing A, Palfi M, Ernerudh J, Kjellberg S, Lindton B. Prevention of recurrent spontaneous abortion by intravenous immunoglobulin: a double-blind placebo-controlled study. Hum Reprod. 1999;14(3):838-841.

134. Stephenson MD, Kutteh WH, Purkiss S, et al. Intravenous immunoglobulin and idiopathic secondary recurrent miscarriage: a multicentered randomized placebo-controlled trial. Hum Reprod. 2010; 25(9):2203-2209.

135. Christiansen OB, Larsen EC, Egerup P, Lunoee L, Egestad L, Nielsen HS. Intravenous immunoglobulin treatment for secondary recurrent miscarriage: a randomised, double-blind, placebo-controlled trial. BJOG. 2015;122(4):500-508.

136. Egerup P, Lindschou J, Gluud C, Christiansen OB; ImmuReM IPD Study Group. The effects of intravenous immunoglobulins in women with recurrent miscarriages: a systematic review of randomised trials with meta-analyses and trial sequential analyses including individual patient data. PLOS ONE. 2015;10(10):e0141588.

137. Wong LF, Porter TF, Scott JR. Immunotherapy for recurrent miscarriage. Cochrane Database Syst Rev. 2014;10:CD000112.

138. Winger EE, Reed JL. Treatment with tumor necrosis factor inhibitors and intravenous immunoglobulin improves live birth rates in women with recurrent spontaneous abortion. Am J Reprod Immunol. 2008; 60(1):8-16.

139. Weber-Schoendorfer C, Oppermann M, Wacker E, et al. Pregnancy outcome after TNF-alpha inhibitor therapy during the first trimester: a prospective multicentre cohort study. Br J Clin Pharmacol. 2015; 80(4):727-739.

140. Roussev RG, Ng SC, Coulam CB. Natural killer cell functional activity suppression by intravenous immunoglobulin, intralipid and soluble human leukocyte antigen-G. Am J Reprod Immunol. 2007; 57(4):262-269.

141. Meng L, Lin J, Chen L, et al. Effectiveness and potential mechanisms of intralipid in treating unexplained recurrent spontaneous abortion. Arch Gynecol Obstet. 2016;294(1):29-39.

142. Scarpellini F, Sbracia M. Use of granulocyte colony-stimulating factor for the treatment of unexplained recurrent miscarriage: a randomised controlled trial. Hum Reprod. 2009;24:2703-2708.

143. Hill JA, Abbott AF, Politch JA. Sperm morphology and recurrent abortions. Fertil Steril. 1994;61(4):776-778.

144. Lewis SE, John Aitken R, Conner SJ, et al. The impact of sperm DNA damage in assisted conception and beyond: recent advances in diagnosis and treatment. Reprod Biomed Online. 2013;27(4):325-337. 
145. Carrell DT, Liu L, Peterson CM, et al. Sperm DNA fragmentation is increased in couples with unexplained recurrent pregnancy loss. Arch Androl. 2003;49(1):49-55.

146. Robinson L, Gallos ID, Conner SJ, et al. The effect of sperm DNA fragmentation on miscarriage rates: a systematic review and meta-analysis. Hum Reprod. 2012;27(10):2908-2917.

147. Absalan F, Ghannadi A, Kazerooni M, et al. Value of sperm chromatin dispersion test in couples with unexplained recurrent abortion. J Assist Reprod Genet. 2012;29(1):11-14.

148. Khadem N, Poorhoseyni A, Jalali M, et al. Sperm DNA fragmentation in couples with unexplained recurrent spontaneous abortions. Andrologia. 2014;46(2):126-130.

149. Agarwal A, Majzoub A, Esteves SC, Ko E, Ramasamy R, Zini A. Clinical utility of sperm DNA fragmentation testing: practice recommendations based on clinical scenarios. Transl Androl Urol. 2016; 5(6):935-950.

150. Haas DM, Ramsey PS. Progestogen for preventing miscarriage. Cochrane Database Syst Rev. 2013;(10):CD003511.

151. Coomarasamy A, Williams H, Truchanowicz E, et al. A randomized trial of progesterone in women with recurrent miscarriages. $N$ Engl J Med. 2015;373(22):2141-2148.

152. Saccone G, Schoen C, Franasiak JM, Scott RT Jr, Berghella V. Supplementation with progestogens in the first trimester of pregnancy to prevent miscarriage in women with unexplained recurrent miscarriage: a systematic review and meta-analysis of randomized, controlled trials. Fertil Steril. 2017;107(2):430-438.

153. Stephenson MD, McQueen D, Winter M, Kliman HJ. Luteal start vaginal micronized progesterone improves pregnancy success in women with recurrent pregnancy loss. Fertil Steril. 2017;107(3):684-690.

154. Romero R, Stanczyk FZ. Progesterone is not the same as $17 \alpha-$ hydroxyprogesterone caproate: implications for obstetrical practice. Am J Obstet Gynecol. 2013;208:421-426.

155. Munne S, Lee A, Rosenwaks Z, Grifo J, Cohen J. Diagnosis of major chromosome aneuploidies in human preimplantation embryos. Hum Reprod. 1993;8(12):2185-2191.
156. Mastenbroek S, Twisk M, van der Veen F, Repping S. Preimplantation genetic screening: a systematic review and meta-analysis of RCTs. Hum Reprod Update. 2011;17(4):454-466.

157. Scott RT Jr, Upham KM, Forman EJ, Zhao T, Treff NR. Cleavagestage biopsy significantly impairs human embryonic implantation potential while blastocyst biopsy does not: a randomized and paired clinical trial. Fertil Steril. 2013;100(3):624-630.

158. Brezina PR, Anchan R, Kearns WG. Preimplantation genetic testing for aneuploidy: what technology should you use and what are the differences? J Assist Reprod Genet. 2016;33(7):823-832.

159. Geraedts J, Sermon K. Preimplantation genetic screening 2.0: the theory. Mol Hum Reprod. 2016;22(8):839-844.

160. Yang Z, Liu J, Collins GS, et al. Selection of single blastocysts for fresh transfer via standard morphology assessment alone and with array CGH for good prognosis IVF patients: results from a randomized pilot study. Mol Cytogenet. 2012;5(1):24.

161. Forman EJ, Hong KH, Ferry KM, et al. In vitro fertilization with single euploid blastocyst transfer: a randomized controlled trial. Fertil Steril. 2013;100(1):100-107.

162. Scott RT Jr, Upham KM, Forman EJ, et al. Blastocyst biopsy with comprehensive chromosome screening and fresh embryo transfer significantly increases in vitro fertilization implantation and delivery rates: a randomized controlled trial. Fertil Steril. 2013;100(3):697-703.

163. Dahdouh EM, Balayla J, García-Velasco JA. Comprehensive chromosome screening improves embryo selection: a meta-analysis. Fertil Steril. 2015;104(6):1503-1512.

164. Gleicher N, Kushnir VA, Barad DH. Preimplantation genetic screening (PGS) still in search of a clinical application: a systematic review. Reprod Biol Endocrinol. 2014;12:22.

165. Sermon K, Capalbo A, Cohen J, et al. The why, the how and the when of PGS 2.0: current practices and expert opinions of fertility specialists, molecular biologists, and embryologists. Mol Hum Reprod. 2016;22(8):845-857.
International Journal of Women's Health

\section{Publish your work in this journal}

The International Journal of Women's Health is an international, peerreviewed open-access journal publishing original research, reports, editorials, reviews and commentaries on all aspects of women's healthcare including gynecology, obstetrics, and breast cancer. The manuscript management system is completely online and includes

\section{Dovepress}

a very quick and fair peer-review system, which is all easy to use. Visit http://www.dovepress.com/testimonials.php to read real quotes from published authors. 